\title{
Correlation between Processing Conditions, Lattice Defect Structure and Mechanical Performance of Ultrafine-Grained Materials
}

\author{
J. GubiczA* \\ Department of Materials Physics, Eötvös Loránd University, \\ Budapest, H-1117, Pázmány Péter sétány 1/A, Hungary
}

\begin{abstract}
The mechanical performance of ultrafine-grained materials is strongly influenced by the lattice defect structure, i.e. the vacancy concentration, the type, arrangement and density of dislocations, the planar fault probability, as well as the amount and character of grain boundaries. In this paper, the correlation between the processing conditions, the lattice defect structure and the plastic behavior of ultrafine-grained materials is overviewed. For the processing route of severe plastic deformation, the influence of applied strain, hydrostatic pressure, as well as melting point, stacking fault energy and alloying on grain size, dislocation density and strength is studied. For nanopowder sintering techniques, the effect of atmosphere, temperature and time of consolidation on lattice defects and mechanical properties is discussed in detail.
\end{abstract}

DOI: 10.12693/APhysPolA.128.479

PACS: 61.72.Dd, 62.20.F-, 61.72.Ff, 81.07.Bc, 62.20.-x, 61.72.Mm

\section{Introduction}

In the last decades ultrafine-grained (UFG) materials have become a focal point of materials science due to their unique physical, chemical and mechanical properties that destine these materials to novel and promising applications. The type and densities of lattice defects have a significant effect on the mechanical performance of UFG materials [1]. For instance, the strength caused by dislocations $\left(\sigma_{\text {disl }}\right)$ can be described by the well-known Taylor formula [2]:

$$
\sigma_{\text {disl }}=\alpha M^{\mathrm{T}} G b \rho^{1 / 2},
$$

where $G$ is the shear modulus, $\rho$ is the dislocation density, $M^{\mathrm{T}}$ is the Taylor factor, $b$ is the magnitude of the Burgers vector and $\alpha$ is a constant. The value of $b$ depends on the type of dislocations, e.g. on the population of the $\langle a\rangle,\langle c\rangle$ and $\langle c+a\rangle$ dislocation slip systems in hexagonal materials. Parameter $\alpha$ is influenced by the arrangement of dislocations, as its value is different for uniform dislocation distribution and for dense dislocation arrangements, such as low-angle grain boundaries or dipolar walls [3]. Another crystal defects, such as vacancies have also an effect on the plastic behavior of UFG materials, since the diffusion coefficient is proportional to the vacancy concentration. Therefore, the deformation mechanisms controlled by vacancy migration (e.g. the dislocation climb) can be accelerated by increase of the vacancy concentration. For instance, in UFG materials processed by severe plastic deformation (SPD) at room temperature (RT) the vacancy concentration reached the equilibrium value characteristic at the melting point $\left(10^{-5}-10^{-4}\right)[4-8]$ which

\footnotetext{
*e-mail: jeno.gubicza@ttk.elte.hu
}

is seventeen orders of magnitude larger than the equilibrium vacancy concentration at $\mathrm{RT}$.

Two-dimensional lattice defects, such as grain boundaries, have also a significant effect on the mechanical performance of UFG materials. The strengthening effect of grain boundaries is usually taken into account by the well-known Hall-Petch formula [9, 10]:

$$
\sigma_{\mathrm{GB}}=k_{Y} d^{-1 / 2} \text {, }
$$

where $\sigma_{\mathrm{GB}}$ is the yield strength increment caused by the grain boundaries, $d$ is the grain size and $k_{y}$ is a constant depending on the material. It is noted that this formula usually loses its validity for grain sizes smaller than several tens of nanometers due to the domination of deformation mechanisms occurring at grain boundaries (e.g. grain boundary sliding). The lower limit of the grain size regime, where the Hall-Petch equation is valid, increases with decrease of the strain rate of deformation [11]. Anyway, Eq. (2) reflects that a higher amount of grain boundaries (boundary area per unit volume) corresponding to a smaller grain size results in a larger yield strength. It should be noted that besides the amount of grain boundaries their character also influences the mechanical performance of UFG materials. Namely, the fraction of special coincidence site lattice (CSL) boundaries strongly affect the ductility and the fatigue behavior of metallic materials. The high fraction of CSL boundaries with low $\Sigma$ values usually yields a higher elongation to failure during tension and a larger number of cycles to failure in fatigue experiments [12]. This special grain boundary structure can be achieved by thermomechanical treatments referred to as grain boundary engineering (GBE).

Former studies [13-15] have shown that the processing conditions of UFG materials influence their lattice defect structure (e.g. concentration of vacancies, density 
and character of dislocations, type and amount of grain boundaries), therefore the properties of UFG materials can be tailored by an appropriate selection of the production methodology. For instance, in the case of UFG copper processed by 8 passes of equal-channel angular pressing (ECAP) at RT the grain size is $200-300 \mathrm{~nm}$ and the main lattice defects inside the grains are vacancies and dislocations [14]. However, in the case of UFG-Cu produced by pulsed electrodeposition the main defects are grown-in twin boundaries inside the grains with the size of $400-500 \mathrm{~nm}$ [13]. This difference has a strong effect on the mechanical behavior. The yield strength of the electrodeposited UFG-Cu was $900 \mathrm{MPa}$ which is more than twice larger than that for the ECAPprocessed $\mathrm{Cu}(400 \mathrm{MPa})$. The higher strength in the former case is caused by the small twin boundary spacing (about $20 \mathrm{~nm}$ ) as twin boundaries are also effective obstacles against dislocation glide. The higher yield strength in UFG materials is usually accompanied by a reduced ductility [16]. However, in electrodeposited $\mathrm{Cu}$ the twin boundaries do not reduce the strain hardening capability of the material, therefore the elongation to failure is the same $(14 \%)$ as for the ECAP-processed sample [13, 14]. It should be noted here that not only the grain boundary structure but in general the whole lattice defect structure can be tailored by an appropriate selection of the processing conditions of UFG materials. Therefore, the extension of "grain boundary engineering" to "crystal defect engineering" is suggested.

In this paper, the correlation between the processing conditions, the lattice defect structure and the mechanical performance in UFG materials is overviewed. The processing methods of UFG materials can be classified into two groups. In the course of "bottom-up" methods the materials are built up from individual atoms, molecules or their clusters (particles), such in electrodeposition or inert gas condensation. In the case of "top-down" methods, the nanosized microstructural units (grains or crystallites) are achieved by refinement of coarse-grained materials. The grain refinement usually occurs by severe plastic deformation that can be carried out either on bulk materials as in the case of ECAP or on powder samples e.g. by milling. In the case of nanomaterials processed by powder metallurgy the classification may be more complex. The consolidation procedures of nanopowders are usually declared as "bottomup" methods but the nanopowders used for sintering can be produced by milling that is a "top-down" procedure. In this review, illustrative examples will be given for the effect of the processing conditions of both "top-down" and "bottom-up" production methods on the defect structure and the mechanical behavior of UFG materials. The influence of strain and hydrostatic pressure applied during SPD, as well as the effect of atmosphere, temperature and time in nanopowder consolidation on lattice defects and mechanical performance of UFG materials are discussed in detail. It is also shown how the melting point, the stacking fault energy, as well as the solute content and the secondary phase particles affect the defect structure and the plastic properties.

\section{Experimental}

In this review, the lattice defect structure in UFG materials is characterized mainly by $\mathrm{X}$-ray diffraction line profile analysis, therefore a brief summary of this technique is presented here. The $\mathrm{X}$-ray line profiles were measured by a high-resolution rotating anode diffractometer (Nonius, FR 591) using $\mathrm{Cu} K_{\alpha}(\lambda=0.15406 \mathrm{~nm})$ radiation. Two-dimensional imaging plates detected the Debye-Scherrer diffraction rings. The line profiles were obtained as a function of the diffraction angle by integrating the two-dimensional intensity distribution along the rings at discrete angle values. The line profiles were evaluated by the convolutional multiple whole profile (CMWP) fitting analysis [17, 18]. In this procedure, the diffraction pattern is fitted by the sum of a background spline and the convolution of the instrumental pattern and the theoretical line profiles related to the crystallite size, dislocations and twin faults. The CMWP method gives the following parameters of the microstructure: the median of the crystallite size distribution $(m)$, the square root of the lognormal variance of the crystallite size distribution $(\sigma)$, the dislocation density, the dislocation arrangement parameter, the parameters of the dislocation contrast factors which can be used for the determination of the prevailing dislocation slip systems and the probabilities of stacking or twin fault. The stronger the screening of the strain fields of dislocation, the smaller the value of the dislocation arrangement parameter. Strong screening of strain fields of dislocations occurs e.g. when dislocations are arranged into dipoles or low-angle grain boundaries. The twin (or stacking) fault probability gives the fraction of faulted planes among those crystal lattice planes which may serve as habit planes of planar faults. The area-weighted mean crystallite size can be calculated from the median and the lognormal variance as $\langle x\rangle_{\text {area }}=m \exp \left(2.5 \sigma^{2}\right)$. More details about theory, methodology and practice of X-ray line profile analysis can be found in [19].

\section{Results and discussion}

\subsection{Evolution of the defect structure} and the mechanical performance in UFG metals as a function of strain applied in SPD-processing

One of the most frequently used SPD method is ECAP that enables the elaboration of bulk UFG or nanomaterials with dimensions of several centimetres in all directions that is favourable in practical applications [20]. One pass of ECAP corresponds to an equivalent strain value of about 1 . The dislocation density increases while the crystallite size decreases with increase of the number of ECAP passes, and their values saturate at the equivalent strain between 2 and 4 , depending on the material and the processing temperature [21-28]. The saturation of the dislocation density is a consequence of the dynamic equilibrium between the multiplication and the 
annihilation of dislocations. The grain size determined by transmission electron microscopy (TEM) has similar evolution as for the crystallite size, however the grain size is usually 2-6 times larger than the crystallite size in SPD-processed UFG materials [1]. This phenomenon can be explained by the fact that coherently scattering domains (crystallites) correspond rather to subgrains in severely deformed microstructures. The reduction in subgrain and grain sizes with increasing imposed strain is attributed to the increase in dislocation density as grain refinement during SPD usually starts by the arrangement of dislocations into low energy configurations such as lowangle grain boundaries. This evolution of the dislocation structure is also indicated by the decrease of the dislocation arrangement parameter determined by $\mathrm{X}$-ray line profile analysis [1]. It is noted that during SPD at high homologous temperatures dynamic recrystallization may also play an important role in grain refinement. When the number of ECAP passes reaches a value of $10-15$, the dislocation density decreases and the crystallite size increases [1]. For instance, in the case of $\mathrm{Cu}$ this change is about $30 \%$, which can be attributed to a structural relaxation in grain/subgrain boundaries by the annihilation of extrinsic dislocations (these dislocations are not needed to accommodate the geometrical misorientation between grains/subgrains) [21]. This recovery is accompanied by a decrease in the grain boundary thickness corresponding to an evolution from non-equilibrium boundaries to a more equilibrated structure.

In accordance with the increase of the dislocation density and the reduction of the grain size, the yield strength of metallic materials processed by SPD increases with increasing imposed strain and saturates at the strain value of about 2-4 [1]. At the same time, the elongation to failure reduces due to the loss of work hardening capability with increase of the defect (dislocations and grain boundaries) density [16]. The structural relaxation (recovery) after 10-15 ECAP passes usually results in an slight reduction of the yield strength and an improvement of the ductility. Dislocations play a major role in hardening caused by SPD in face-centered cubic (fcc) metals and solid solutions, as the yield strength calculated by the Taylor equation (see Eq. (1)) gives the majority of the value determined by mechanical tests [1]. This observation can be explained by the fact that a large fraction of grain boundaries consists of dislocations in SPDprocessed metallic materials, therefore their hardening effect is also taken into account in the Taylor formula. In order to achieve very high strength during SPD, it should be clarified what the main factors are that influence the saturation dislocation density. In the next three sections the effect of the SPD-processing conditions and the properties of materials on the defect structure and strength is discussed.

\subsection{Effect of solute atoms and precipitates} on defect structure and strength in SPD-processed alloys

Alloying increases the maximum dislocation density and the minimum grain size achieved by SPD due to the pinning effect of solute atoms on lattice defects, thereby hindering their annihilation [23, 1]. As an example, Fig. 1 shows the saturation values of the dislocation density and the grain size obtained after 8 passes of ECAP at room temperature as a function of $\mathrm{Mg}$ concentration in $\mathrm{Al}(\mathrm{Mg})$ solid solutions. In pure $\mathrm{Al}$ the saturation grain size is $1200 \mathrm{~nm}$ while $3 \mathrm{wt} . \% \mathrm{Mg}$ alloying leads to a reduction of the grain size to $300 \mathrm{~nm}$. It is noted that although the minimum grain size in $\mathrm{Al}-3 \% \mathrm{Mg}$ alloy is only 4 times smaller than that in pure $\mathrm{Al}$, the maximum dislocation density is approximately 13 times higher. Accordingly, the yield strength increases by a factor of 3.3 due to alloying with $3 \% \mathrm{Mg}$. The solute atoms increase the strength directly by enhancing the critical resolved shear stress of dislocation glide and also indirectly by increasing the dislocation density. For Al processed by 8 ECAP passes at room temperature the direct and indirect strength contributions are 20 and $100 \mathrm{MPa}$, respectively. The addition of $3 \% \mathrm{Mg}$ to $\mathrm{Al}$ increases the direct and indirect strength terms by 30 and $250 \mathrm{MPa}$, respectively. This observation suggests that solute atoms in SPD-processed alloys enhance the strength mainly indirectly by increase of the dislocation density.

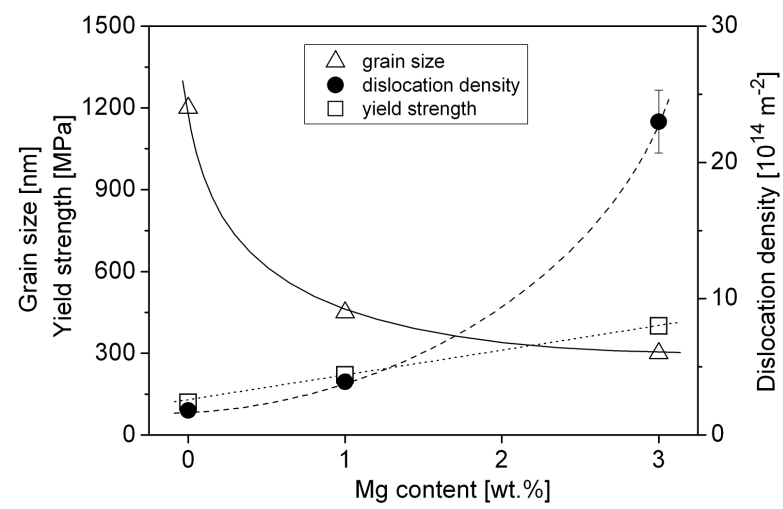

Fig. 1. The grain size, the dislocation density and the yield strength as a function of $\mathrm{Mg}$ concentration in UFG-Al processed 8 passes of ECAP at room temperature.

Secondary phase particles dispersed in the matrix grains also increase the dislocation density and decrease the grain size. For instance, in Al6082 alloy (composition: $97 \% \mathrm{Al}, 0.7-1.3 \% \mathrm{Si}, 0.6-1.2 \% \mathrm{Mg}$ and $0.4-1 \% \mathrm{Mn}$ in wt.\%) $\mathrm{Mg}_{2} \mathrm{Si}$ and $\mathrm{Mn}_{12} \mathrm{Si}_{7} \mathrm{Al}_{5}$ particles hinder the annihilation of lattice defects during 8 ECAP passes at room temperature, resulting in a fourfold reduction and a threefold increment in the grain size and the dislocation density, respectively [26]. The direct and indirect contributions of these precipitates to hardening are comparable (80 and $65 \mathrm{MPa}$, respectively).

\subsection{Influence of melting point and stacking fault energy on defect structure}

As formerly mentioned, the saturation dislocation density is a result of the dynamic equilibrium between the 
multiplication and the annihilation of dislocations during SPD-processing. The annihilation of dislocations is thermally activated, therefore the maximum dislocation density and the minimum crystallite (or grain) size are expected to be higher and lower, respectively, for SPDprocessing carried out at lower homologous temperatures. Therefore, when SPD is performed at room temperature, the saturation dislocation density and crystallite size should be larger and smaller, respectively, for materials with higher melting point. This is roughly valid for pure fcc metals processed by 8 passes of ECAP at room temperature, as shown in Fig. 2. The data are taken

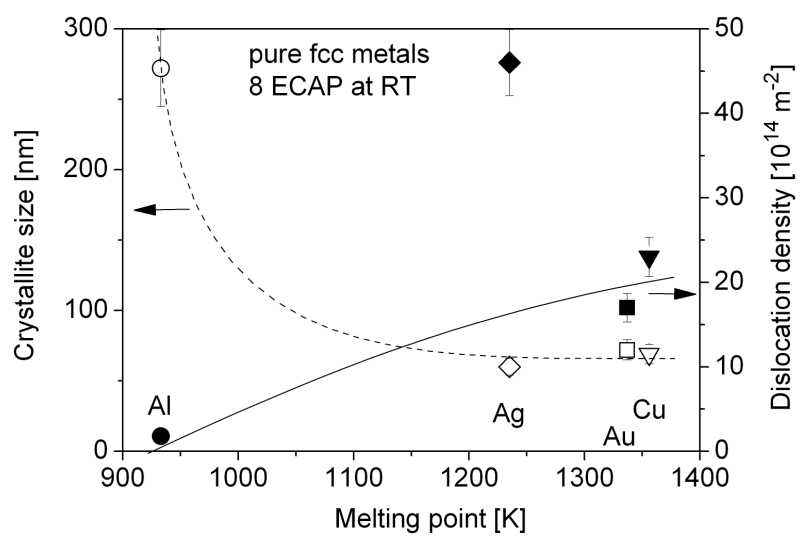

Fig. 2. The crystallite size and the dislocation density as a function of the melting point in pure UFG fcc metals processed by 8 passes of ECAP at room temperature.

from Ref. [1]. However, the saturation dislocation density in $\mathrm{Ag}$ is much larger than the values obtained for metals with higher melting point. The extremely large saturation dislocation density in $\mathrm{Ag}$ among other fcc metals can be explained by its very low stacking fault energy (SFE). The lower SFE usually associated with larger splitting distance between partials in dissociated dislocations. Therefore, there is a high degree of dislocation dissociation in $\mathrm{Ag}$ which hinders the annihilation processes (cross-slip and climb) of dislocations during SPD, resulting in very high dislocation density after ECAP. It is worth to note that the saturation grain size in $\mathrm{Ag}$ is not smaller than the values obtained for other fcc metals, i.e. low SFE in pure metals does not cause smaller grain size. This can be explained by the difficult arrangement of dislocations into boundaries due to their highly dissociated state, as well as by the easy recrystallization in low SFE pure materials which increases the minimum grain size. The low SFE is associated with low twin fault energy and the twinned volumes act as nuclei for recrystallization. It should be noted that in some metallic materials the low $\mathrm{SFE}$ can be reached by alloying (see e.g. $\mathrm{Cu}-\mathrm{Zn}$ or $\mathrm{Cu}-\mathrm{Al}$ alloys). In this case, the effects of alloying and low SFE on defect structure formed during SPD cannot be separated, and the very small grain size in these alloys is often explained by the low SFE [29, 30]. The results obtained in pure $\mathrm{Ag}$ suggests that in low SFE alloys the small grain size can be achieved due to the retarding effect of alloying elements on recrystallization. It is also noted that the influence of melting point and SFE on maximum dislocation density and minimum grain size is similar for other SPD-processed crystal structures (e.g. body centered cubic or hexagonal close packed) [31, 32].

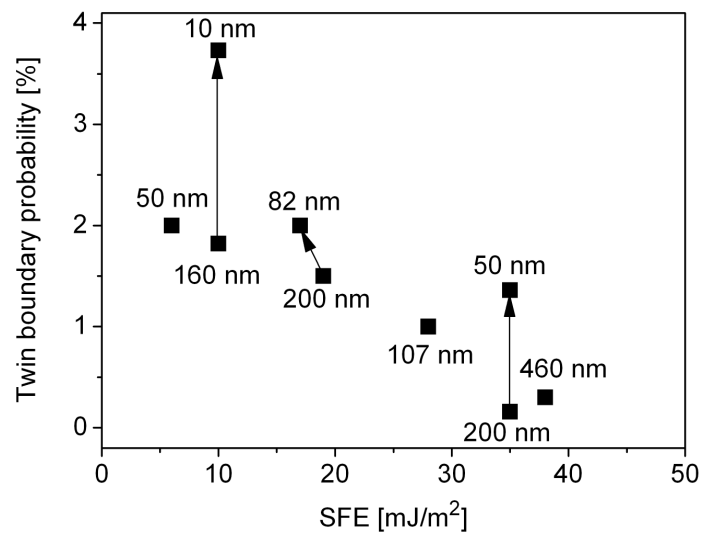

Fig. 3. The twin boundary probability as a function of SFE for different UFG fcc metals and solid solutions processed by SPD (ECAP or HPT) at room temperature. The grain size values are indicated at the datum points.

It has been shown that the splitting distance between partials depends not only on the shear modulus and the SFE but also on the grain size in fcc metals [33]. The smaller the grain size, the higher the splitting distance between the partial dislocations in nanocrystalline fcc materials, as this reduces the energy of the dissociated dislocations emitted from the grain boundary. Therefore, stacking faults are easily formed in nanograins and two stacking faults on neighboring lattice planes yield a twin lamella. The growth of this lamella can occur due to stresses, therefore twinning becomes a dominant deformation mechanism with decrease of grain size in fcc metals [33]. As a consequence, the reduction of both SFE and grain size result in a higher twin boundary probability, as shown in Fig. 3. In this figure the twin boundary probability is plotted as a function of SFE for fcc metals and solid solutions processed by SPD. The data are taken from Ref. [1]. The grain size values are also given at the datum points. For a given SFE value, the higher twin boundary probability is related to a smaller grain size, as indicated the arrows in Fig. 3. It is noted that the reduction in grain size in hexagonal materials yields an opposite tendency, as the high stresses at the grain boundaries facilitate the activation of pyramidal dislocations instead of twinning.

\subsection{Effect of hydrostatic pressure applied during SPD on lattice defects and strength}

High pressure torsion (HPT) is an SPD-processing technique that applies very high pressure $(2-10 \mathrm{GPa})$ during plastic deformation [34]. The comparison of 
the microstructures developed during HPT and ECAP can reveal the influence of hydrostatic pressure on defect structure in SPD-processed UFG materials. During ECAP-processing (without the application of back pressure) the hydrostatic pressure is smaller at least by one order of magnitude than in the case of HPT. Therefore, it is expected that the high pressure in HPT leads to a slower diffusion due to the increase of the vacancy migration enthalpy which can be given as $H_{\mathrm{VM}}=E_{\mathrm{VM}}+p V_{\mathrm{VM}}$, where $E_{\mathrm{VM}}$ is the vacancy migration energy, $p$ is the hydrostatic pressure component of the stress field and $V_{\mathrm{VM}}$ is the vacancy migration volume. The slower diffusion hinders the annihilation of dislocations that might result in an increase in the dislocation density and therefore it yields a smaller grain size. Figures $4 a-c$ show the grain size, the dislocation density and the yield strength, respectively, for $2 \mathrm{~N} 5$ purity $\mathrm{Al}, \mathrm{Al}-1 \% \mathrm{Mg}$ alloy, oxygenfree (99.98\% purity) $\mathrm{Cu}$ and interstitial-free (IF) steel. The data are taken from Refs. [15, 23, 35, 36]. It can be seen that although HPT results in a smaller grain size, the dislocation density is similar as after ECAP, except the case of $\mathrm{Cu}$, where the dislocation density is considerably higher after HPT-processing. The question is why the dislocation density in other materials is not higher after HPT compared to ECAP. Most probably, the dislocation density under the large pressure applied during HPT was higher than in ECAP-processing, however when the pressure was released a large fraction of dislocations annihilates, as shown in Ref. [37]. In the case of $\mathrm{Cu}$, the relatively low SFE (compared to other materials in Fig. 4) retarded this annihilation process, as

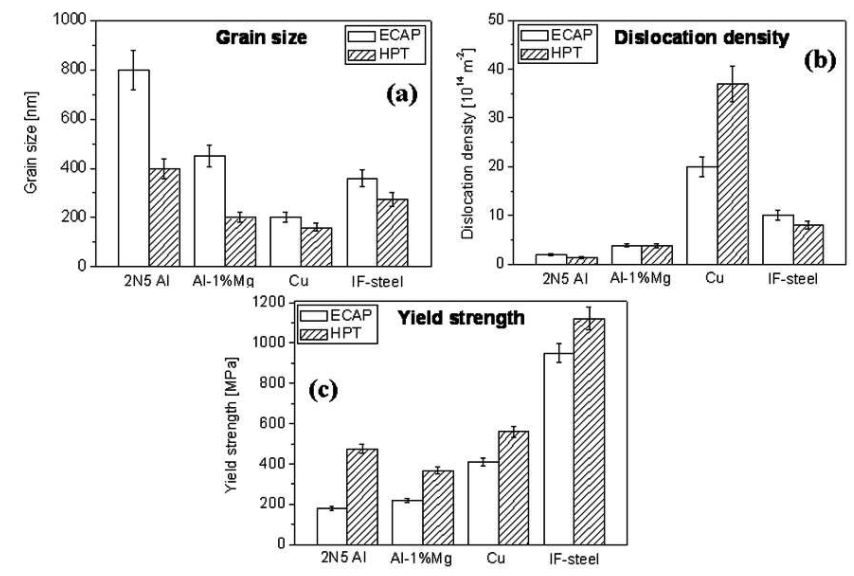

Fig. 4. Comparison of the saturation grain size (a), dislocation density (b) and yield strength (c) in different UFG materials processed by ECAP and HPT at room temperature.

discussed in the previous section, hereby resulting in a higher dislocation density after HPT than that obtained in ECAP-processing. Anyway, either the smaller grain size or the higher dislocation density after HPT yields a higher yield strength compared to ECAP, as shown in Fig. 4c.
3.5. Influence of initial powder particle size, time, temperature and atmosphere of sintering on defect structure and mechanical performance of UFG metals processed by powder metallurgy

Besides SPD techniques, consolidation of nanopowders is another route to produce UFG materials. In the following, the influence of the initial powder particle size, the time and temperature of sintering and the atmosphere used in powder processing on the microstructure and plastic properties will be illustrated on Ni. One sample was produced from a nanopowder with the average particle size of about $100 \mathrm{~nm}$ by hot-isostatic pressing (HIP) [38]. Before HIP, the glass containing the powder was broken in a glove-box and subsequently encapsulated in a steel can and sealed under inert gas (Ar) to prevent oxidation. HIP processing was performed at $140 \mathrm{MPa}$ and $700{ }^{\circ} \mathrm{C}$ for $150 \mathrm{~min}$. In order to investigate the effect of time and temperature of consolidation on the microstructure, another sample was also processed from the same powder under Ar atmosphere by sparkplasma sintering (SPS). During SPS, high current pulses $\left(1000 \mathrm{~A} / \mathrm{cm}^{2}\right)$ facilitated the consolidation, thereby the time and temperature of sintering were reduced to $1 \mathrm{~min}$ and $500{ }^{\circ} \mathrm{C}$, respectively [38]. The effect of powder processing atmosphere was studied by consolidating another sample by SPS under the same conditions but in this case the capsule containing the powder was broken in air (not in Ar) and rapidly transferred to a graphite mould. Finally, in order to study the effect of the initial powder particle size on the microstructure, a fourth sample was consolidated from a $\mathrm{Ni}$ powder with the average particle size of $50 \mathrm{~nm}$ by SPS under the same conditions as for the previous specimen.

It was found that in the case of the initial powder particle size of $100 \mathrm{~nm}$, sintering caused a graingrowth to about 400 and $300 \mathrm{~nm}$ for HIP and SPS, respectively. The lower time and temperature in SPSprocessing reduced the grain-growth during consolidation. The smaller the powder particle size, the smaller the grain size in the sintered material, as for the initial powder particle size of $50 \mathrm{~nm}$, the grain size in the consolidated sample was only $250 \mathrm{~nm}$.

$\mathrm{X}$-ray diffraction and energy-filtered TEM investigations revealed that there is a native crystalline $\mathrm{NiO}$ layer on the surface of Ni powder particles [38]. In the sintered materials this phase appears in the form of dispersoids in the Ni matrix. When the powder is processed in Ar atmosphere the $\mathrm{NiO}$ content does not change during sintering as a result of the careful isolation of the sample from air. On the other hand, if the powder processing was carried out in air, the $\mathrm{NiO}$ content in the consolidated samples is significantly higher than in the initial powder. For smaller initial powder particle size, the fraction of $\mathrm{NiO}$ phase is higher due to the larger specific surface area. The powder processing atmosphere (i.e. the $\mathrm{NiO}$ content) has no considerable effect on the grain size $(\approx 300 \mathrm{~nm})$, the dislocation density $\left(\approx 5 \times 10^{14} \mathrm{~m}^{-2}\right)$ and the twin boundary probability $(\approx 0.3 \%)$ in the sintered materials. 
This can be explained by the high sintering temperature which facilitates the bypass of $\mathrm{NiO}$ particles by dislocations. Additionally, a large fraction of these $\mathrm{NiO}$ particles are located at the grain boundaries which has no effect on the dislocation multiplication in the grain interiors.

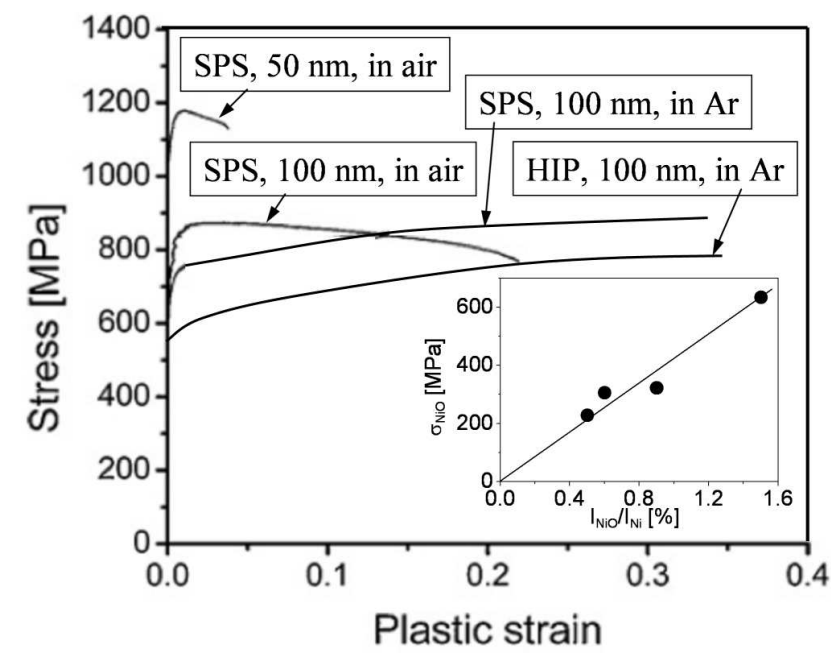

Fig. 5. Stress-strain curves obtained by compression for UFG-Ni consolidated by HIP or SPS under different conditions. The inset shows the strengthening contribution of $\mathrm{NiO}$ particles as a function of the ratio of intensities of $\mathrm{NiO}$ and $\mathrm{Ni}$ phases in the X-ray diffractograms.

Therefore, it can be concluded that in sintered UFG$\mathrm{Ni}$ material $\mathrm{NiO}$ phase has only a direct strengthening effect which is illustrated in Fig. 5 where the stressstrain curves obtained by compression are plotted. For the samples processed in Ar from the initial powder with the particle size of $100 \mathrm{~nm}$, SPS results in a higher yield strength than in the case of HIP, since the grain-growth during the former procedure is limited due to the shorter sintering time and the lower temperature. The powder processing in air during SPS increases the yield strength due to the higher $\mathrm{NiO}$ content [39]. The smaller initial powder particle size in SPS-processing also results in a larger strength which can be explained by a combined effect of the smaller sintered grain size and the higher $\mathrm{NiO}$ content. The strengthening contribution of $\mathrm{NiO}$ dispersoids can be estimated as the deviation of the measured strength from the values predicted by the HallPetch equation [39]. The strength caused by the NiO phase for the studied four samples is plotted as a function of the $\mathrm{NiO}$ content in the inset of Fig. 5. It is noted that the fraction of $\mathrm{NiO}$ phase is estimated as the ratio of the intensities of $\mathrm{NiO}$ and $\mathrm{Ni}$ phases in the X-ray diffractograms. A good correlation between the strength contribution and the fraction of $\mathrm{NiO}$ phase is observed. It should also be noted that for the samples processed in air, the high oxide content yields an early softening due to cracking (see in Fig. 5). The oxide phase at grain boundaries weakens the bonding between $\mathrm{Ni}$ grains, resulting in an easier cracking during deformation [38].
3.6. Effect of carbon nanotube addition on lattice defect structure and mechanical performance of UFG metallic materials

Carbon nanotubes (CNTs) are often used as filler materials in composites due to their unique properties (e.g. high elastic modulus, low density, large aspect ratio) [40]. Metal matrix-CNT composites are usually processed by powder metallurgy including the blending of CNTs with the powder of the metal matrix by highenergy milling and then the consolidation of the powder blend $[41,42]$. The latter step can be carried out by HPT, as in this case an UFG microstructure is achieved in the matrix, yielding a further enhancement of the yield strength. In the following, the effect of the addition of CNTs on the defect structure and the hardness of metal matrices will be illustrated on a $\mathrm{Cu}-\mathrm{CNT}$ composite processed from $\mu \mathrm{m}$ sized $\mathrm{Cu}$ particles and 3 vol.\% multi-walled CNTs (MWNTs) by high-energy milling and subsequent two-step consolidation procedure including cold isostatic pressing and HPT at room temperature. The number of turns and the pressure in HPT-processing were 10 and $2.5 \mathrm{GPa}$, respectively [42]. An additional sample from the pure $\mathrm{Cu}$ powder was also consolidated under the same conditions.

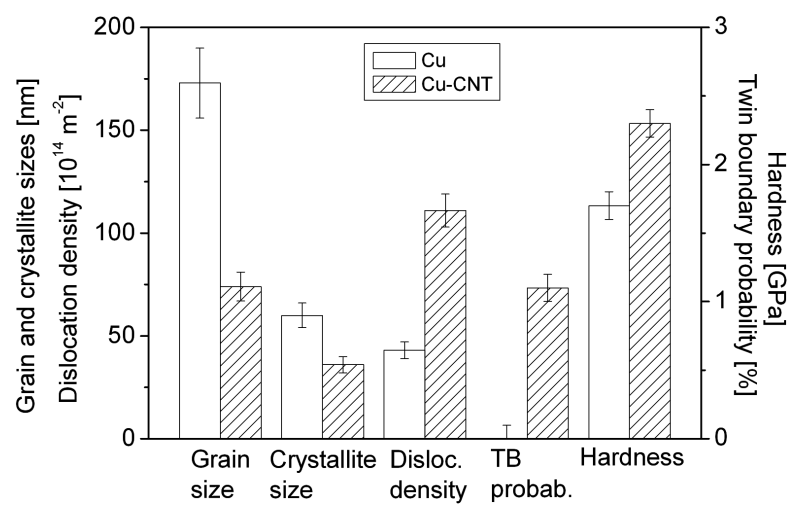

Fig. 6. Comparison of the grain and crystallite sizes, the dislocation density, the twin boundary probability and the hardness of pure $\mathrm{Cu}$ and $\mathrm{Cu}-\mathrm{CNT}$ composite consolidated by HPT at room temperature.

Figure 6 shows that the addition of CNTs to $\mathrm{Cu}$ yields smaller grain and crystallite sizes by a factor of two, as well as almost three times larger dislocation density due to the pinning effect of CNTs on lattice defects (dislocations and grain boundaries). In pure $\mathrm{Cu}$ twinning is marginal, while in the composite considerable twin boundary probability is observed. The more active twin formation can be explained by the higher stress level in dislocation pile ups at glide obstacles (e.g. at LomerCottrel locks and grain boundaries), as CNTs hinder the escape of dislocations from these pile-ups. If the local stresses at these obstacles exceed the critical stress for twin nucleation, deformation twins are formed. Figure 6 also shows that the hardness increases by a factor of $\approx 1.4$ 
due to the additon of CNTs. The hardness enhancement is in quantitative agreement with the increase of the strengthening contribution of dislocations [42], therefore CNTs have rather an indirect hardening effect, via increase of the crystal defect density. The direct strengthening effect of CNTs is marginal as they are encircled by dislocation loops formed during consolidation by HPT, therefore the moving dislocations inside $\mathrm{Cu}$ grains interact with these loops instead of CNTs.

\section{Conclusions}

In this paper illustrative examples for the correlation between processing conditions, defect structure and mechanical performance of UFG materials were presented. The following conclusions have be drawn from the results:

1. The defect structure and the strength of SPDprocessed bulk UFG metallic materials are strongly influenced by the route and the strain of SPD processing. In the case of room temperature SPD, a maximum in the dislocation density and a minimum in the grain size are achieved at the imposed strain of about 2-4. HPT results in a smaller grain size and a higher yield strength compared to ECAP, however the dislocation density values are similar after the two different processes, except the case of $\mathrm{Cu}$. Most probably, the slower vacancy migration caused by the higher hydrostatic pressure applied in HPT yields a higher saturation dislocation density during processing, however a fraction of dislocations annihilated, when the pressure is released. In the case of $\mathrm{Cu}$, the relatively low SFE retards this dislocation annihilation, thereby preserving the higher dislocation density after HPT.

2. Dislocations play a major role in hardening caused by SPD. The maximum dislocation density and the minimum grain size obtained by SPD at room temperature are higher and lower, respectively, for larger solute content, higher melting point and lower SFE of the processed material. The annihilation of dislocations is thermally activated, therefore the maximum dislocation density is higher while the minimum crystallite size at room temperature is smaller for higher melting point. For low SFE materials, the high degree of dislocation dissociation hinders the annihilation of dislocations during SPD. The solute atoms increase the strength mainly indirectly by increase of the dislocation density. In precipitate-hardened alloys the direct and indirect hardening contributions of precipitates are comparable.

3. Twinning becomes more significant in the SPDprocessed fcc materials with decrease of both SFE and grain size. The reduction in grain size in hexagonal materials yields an opposite tendency, as the high stresses at the grain boundaries facilitate the activation of pyramidal dislocations instead of twinning.
4. The strain to failure decreases with increase of strain during SPD. However, the ductility can be partly regained while the high strength retains with the application of very large imposed strains (at about 10-20) during SPD.

5. The smaller initial powder particle size, the lower time and temperature of sintering yield smaller grain size in the consolidated material, resulting in higher strength. The oxygen content in the atmosphere of powder processing has no considerable effect on the grain size, the dislocation density and the twin boundary probability in the sintered materials. Therefore, the oxide phase formed during sintering has only a direct strengthening effect. The oxide phase at grain boundaries weakens the bonding between grains, resulting in an easier cracking during deformation.

6. In metal matrix-CNT composites, nanotubes strengthen the composite mainly indirectly by increase of the dislocation density. The nanotubes impede the escape of dislocations from pile-ups, thereby increasing the stress level and resulting in an easier twinning in fcc metal matrices.

\section{Acknowledgments}

The author is grateful for his cooperating partners, the groups of Profs. T.G. Langdon, S. Dobatkin, M. Janecek, G. Dirras and H.S. Kim, for providing the studied UFG materials and performing the complementary investigations. This work was supported by the Hungarian Scientific Research Fund, OTKA, Grant No. K-109021.

\section{References}

[1] J. Gubicza, Defect Structure in Nanomaterials, Woodhead Publishing, Cambridge 2012.

[2] G.I. Taylor, J. Inst. Met. 62, 307 (1938).

[3] F. Hernandez Olivares, J. Gil Sevillano, Acta Metall. 35, 631 (1987).

[4] E. Schafler, G. Steiner, E. Korznikova, M. Kerber, M.J. Zehetbauer, Mater. Sci. Eng. A 410-411, 169 (2005).

[5] D. Setman, E. Schafler, E. Korznikova, M.J. Zehetbauer, Mater. Sci. Eng. A 493, 116 (2008).

[6] R. Kuzel, M. Janecek, Z. Matej, J. Cizek, M. Dopita O. Srba, Metall. Mater. Trans. A 41, 1174 (2010).

[7] J. Cizek, M. Janecek, O. Srba, R. Kuzel, Z. Barnovska, I. Prochazka, S. Dobatkin, Acta Mater. 59, 2322 (2011).

[8] Z. Hegedûs, J. Gubicza, M. Kawasaki, N.Q. Chinh, K. Süvegh, Z. Fogarassy, T.G. Langdon, J. Mater. Sci. 48, 1675 (2013).

[9] E.O. Hall, Proc. Phys. Soc. B 64, 747 (1951).

[10] N.J. Petch, J. Iron. Steel Inst. 174, 25 (1953).

[11] M.J. Zehetbauer, Y. Estrin, in: Bulk Nanostructured Materials, Eds. M.J. Zehetbauer, Y.T. Zhu, WileyVCH, Weinheim 2009, p. 109. 
[12] S. Kobayashi, M. Hirata, S. Tsurekawa, T. Watanabe, Proc. Eng. 10, 112 (2011).

[13] L. Lu, Y. Shen, X. Chen, L. Qian, K. Lu, Science 304, 422 (2004).

[14] S.V. Dobatkin, J.A. Szpunar, A.P. Zhilyaev, J.Y. Cho, A.A. Kuznetsov, Mater. Sci. Eng. A 462 , 132 (2007).

[15] J. Gubicza, S.V. Dobatkin, E. Khosravi, A.A. Kuznetsov, J.L. Lábár, Mater. Sci. Eng. A 528, 1828 (2011).

[16] N. Tsuji, Y. Ito, Y. Saito, Y. Minamino, Scr. Mater. 47, 893 (2002)

[17] G. Ribárik, J. Gubicza, T. Ungár, Mater. Sci. Eng. A 387-389, 343 (2004).

[18] L. Balogh, G. Ribárik, T. Ungár, J. Appl. Phys. 100, 023512 (2006)

[19] J. Gubicza, X-Ray Line Profile Analysis in Materials Science, IGI-Global, Hershey 2014.

[20] R.Z. Valiev, T.G. Langdon, Prog. Mater. Sci. 51, 881 (2006).

[21] J. Gubicza, N.Q. Chinh, J.L. Lábár, S. Dobatkin, Z. Hegedûs, T.G. Langdon, J. Alloys Comp. 483, 271 (2009)

[22] F. Dalla Torre, R. Lapovok, J. Sandlin, P.F. Thomson, C.H.J. Davies, E.V. Pereloma, Acta Mater. 52 , 4819 (2004).

[23] J. Gubicza, N.Q. Chinh, Z. Horita, T.G. Langdon, Mater. Sci. Eng. A 387-389, 55 (2004).

[24] J. Gubicza, L. Balogh, R.J. Hellmig, Y. Estrin, T. Ungár, Mater. Sci. Eng. A 400-401, 334 (2005).

[25] E. Schafler, G. Steiner, E. Korznikova, M. Kerber, M.J. Zehetbauer, Mater. Sci. Eng. A 410-411, 169 (2005).

[26] J. Gubicza, N.Q. Chinh, Gy. Krállics, I. Schiller, T. Ungár, Curr. Appl. Phys. 6, 194 (2006).
[27] J. Gubicza, N.Q. Chinh, J.L. Lábár, Z. Hegedûs, T.G. Langdon, Mater. Sci. Eng. A 527, 752 (2010).

[28] K. Máthis, T. Krajnák, R. Kuzel, J. Gubicza, J. Alloys Comp. 509, 3522 (2011).

[29] S. Qu, X.H. An, H.J. Yang, C.X. Huang, G. Yang, Q.S. Zang, Z.G. Wang, S.D. Wu, Z.F. Zhang, Acto Mater. 57, 1586 (2009)

[30] L. Balogh, T. Ungár, Y. Zhao, Y.T. Zhu, Z. Horita, C. Xu, T.G. Langdon, Acta Mater. 56, 809 (2008).

[31] F.A. Mohamed, Acta Mater. 51, 4107 (2003).

[32] F.A. Mohamed, Mater. Sci. Eng. A 527, 2157 (2010).

[33] Y.T. Zhu, X.Z. Liao, X.L. Wu, Prog. Mater. Sci. 57, 1 (2012).

[34] A.P. Zhilyaev, T.G. Langdon, Prog. Mater. Sci. 53 , 893 (2008).

[35] O. Andreau, J. Gubicza, N.X. Zhang, Y. Huang, P. Jenei, T.G. Langdon, Mater. Sci. Eng. A $\mathbf{6 1 5}$ 231 (2014)

[36] M. Janecek, T. Krajnák, J. Stráská, J. Cízek, D.J. Lee, H.S. Kim, J. Gubicza, IOP Conf. Series Mater. Sci. Eng. 63, 012055 (2014).

[37] E. Schafler, Scr. Mater. 62, 423 (2010).

[38] J. Gubicza, H.-Q. Bui, F. Fellah, G.F. Dirras, J. Mater. Res. 24, 217 (2009).

[39] Q.H. Bui, G. Dirras, S. Ramtani, J. Gubicza, Mater Sci. Eng. A 527, 3227 (2010).

[40] V. Viswanathan, T. Laha, K. Balani, A. Agarwal, S. Seal, Mater. Sci. Eng. R 54, 121 (2006).

[41] H. Li, A. Misra, Y. Zhu, Z. Horita, C.C. Koch, T.G. Holesinger, Mater. Sci. Eng. A 523, 60 (2009).

[42] P. Jenei, E.Y. Yoon, J. Gubicza, H.S. Kim, J.L. Lábár, T. Ungár, Mater. Sci. Eng. A 528, 4690 (2011). 